\title{
O PRINCÍPIO DO POLUIDOR-PAGADOR E A TEORIA DO RISCO INTEGRAL COMO FORMA DE COIBIR, EM ÂMBITO CÍVEL, OS DANOS AO MEIO AMBIENTE
}

\author{
Sabrina Frigotto \\ André Lemuel Ferreira Krieguer ${ }^{2}$ \\ Pedro Willimann dos Anjos \\ Gedson Pagnussatt ${ }^{4}$ \\ Recebido em 05/08/2021 \\ Aceito em 11/09/2021
}

\begin{abstract}
RESUMO
O direito ambiental é, nos tempos modernos, tido como fundamental, sobretudo com a contemporânea ascensão dos direitos sociais. A responsabilização por eventuais danos a este bem de caráter coletivo pode ocorrer em âmbito civil, administrativo e, em ultima ratio, penal. O presente estudo teve por objetivo fazer a interligação entre princípios ambientais de aplicação civil, trazendo à tona a necessidade incontestável de reparação integral e responsabilidade solidária por eventuais lesões, visando sempre o bem comum. Chegou-se, por fim, ao entendimento de que a prevenção é o melhor meio a ser seguido, entretanto, quando já restar configurado prejuízo ambiental, a reparação deve ser efetiva de modo a devolver a coisa ao status quo original ou pecuniária, pelo princípio do poluidor-pagador. Para os fins buscados, quanto aos aspectos metodológicos, a pesquisa pode ser classificada como de natureza básica, com abordagem qualitativa, objetivo exploratório e bibliográfico do tipo narrativo.
\end{abstract}

PALAVRAS-CHAVE: Direito ambiental. Direito civil. Responsabilização. Reparação integral.

\section{THE POLLUTOR-PAYER PRINCIPLE AND THE THEORY OF INTEGRAL RISK}

\section{AS A WAY TO REPRESS, IN CIVIL SCOPE, DAMAGE TO THE ENVIRONMENT}

\begin{abstract}
Environmental law is considered fundamental in modern times, especially with the contemporary rise of social rights. Liability for eventual damages to this collective asset can occur in the civil, administrative and, ultimately, criminal law. The present study aimed to interconnect environmental principles of civil application, highlighting the indisputable need for comprehensive repair and several liability for possible injuries, always aiming at the common good. Finally, we came to the understanding that prevention is the best way to be followed, however, when environmental damage remains,
\end{abstract}

\footnotetext{
${ }^{1}$ Acadêmica da 6 a fase do Curso de Direito da Universidade Alto Vale do Rio do Peixe Campus Fraiburgo. Email: sabrinafrigotto19@gmail.com.

${ }^{2}$ Acadêmico da 6 a fase do curso de Direito da Universidade Alto Vale do Rio do Peixe Campus Fraiburgo. E-mail: andrelfkrieguer@gmail.com.

${ }^{3}$ Acadêmico da $6{ }^{\text {a }}$ fase do curso de Direito da Universidade Alto Vale do Rio do Peixe Campus Fraiburgo. E-mail: pwillemann32@gmail.com.

${ }^{4}$ Bacharel em direito, especialista em Direito Civil e Processo Civil, advogado, professor universitário nas disciplinas de Direito Civil, Processo Civil e Direito do Consumidor da Universidade Alto Vale do Rio do Peixe. E-mail: gedson.adv@hbinfo.com.br.
} 
the repair must be effective in order to return the thing to the original or pecuniary, by the principle polluter pays. For the purposes sought, regarding the methodological aspects, the research can be classified as basic in nature, with a qualitative approach, exploratory and bibliographic objective of the narrative type.

Keywords: Environmental law. Civil law. Liability. Integral repair.

\section{INTRODUÇÃO}

Com a Revolução Industrial ocorrida no século XX, um grande movimento econômicosocial de massificação dos meios de produção e consumo, dominou as nações. É claro que, inicialmente, este marco histórico foi visto como um meio gerador de progresso, todavia, com o correr dos anos, esta evolução produtiva avassaladora também deixou um rastro de destruição.

A produção em larga escala traz a queda de preços, e com isso a comercialização de produtos acessíveis a maior parte da população. A exploração de minérios e a geração de energia também são exemplos de meios que trouxeram grande evolução a vida em comunidade. No entanto, o ser humano por vezes falha quando, na busca por seus interesses individuais, agride o meio ambiente, gerando impactos a coletividade.

O presente estudo, portanto, irá analisar princípios de direito ambiental que terão repercussão na esfera cível. Com destaque ao preceito do poluidor-pagador e da precaução, ambos recepcionados pelo ordenamento jurídico brasileiro.

Terá o escopo inclusive de esclarecer as questões relativas a responsabilidade civil objetiva, integral e solidária em âmbito de lesões ambientais. Para levar ao conhecimento geral que o agente que fere o interesse público não restará impune, respondendo na forma da lei e em consonância com a jurisprudência vigente.

\section{PRINCÍPIOS DO DIREITO AMBIENTAL E SUAS REPERCUSSÕES PARA A RESPONSABILIDADE CIVIL}

O ordenamento jurídico brasileiro é composto por normas que se dividem em regras e princípios. As primeiras traduzem consequências expressas, determinadas, enquanto os princípios possuem caráter mais abrangente, com aplicação a uma gama maior de casos. Dentre os mais relevantes princípios do direito ambiental, destaca-se o do poluidor-pagador, diretamente ligado ao âmbito da responsabilidade civil (SOUZA, 2014).

A conceituação de poluidor encontra-se expressa no inciso IV do artigo $3^{\circ}$ da Lei 6.938/81, a qual estabelece a Política Nacional do Meio Ambiente, observe-se o referido 
diploma: "poluidor: a pessoa física ou jurídica, de direito público ou privado, responsável direta ou indiretamente por atividade causadora de degradação ambiental” (BRASIL, 1981).

Da referida norma extrai-se que o agente causador de degradação ao ambiente fica obrigado a promover a efetiva reparação. Esta pode ser feita pela conversão do dano em pecúnia, ou, o que seria mais adequado, mas nem sempre é possível, a restauração efetiva com o retorno ao status quo, ou seja, ao modo como era antes do ocorrido (SOUZA, 2014).

Tal princípio encontra apoio legal na forma do artigo $225, \S 3^{\circ}$ da Constituição Federal de 1988:

$\S 3^{\circ}$ - As condutas e atividades consideradas lesivas ao meio ambiente sujeitarão os infratores, pessoas físicas ou jurídicas, a sanções penais e administrativas, independentemente da obrigação de reparar os danos causados (BRASIL, 1988).

Importante ressaltar que os direitos sociais, em especial ao meio ambiente, ponto chave do presente estudo, presentes na Carta Magna Brasileira foram o resultado de um movimento mundial que teve início na década de setenta. A Organização das Nações Unidas (ONU), no ano de 1972, realizou a Conferência de Estocolmo, da qual resultou uma declaração internacional acerca do meio ambiente que impulsionou a criação, pelos Estados, de novas leis com extensa proteção ao ambiente (SOUZA, 2014).

A posterior Declaração do Rio de Janeiro (1992) assentou o entendimento acerca do poluidor-pagador, disposto na forma do princípio dezesseis da conferência. Este dispositivo declara que o agente poluidor deve arcar com os custos gerados por sua poluição, e também o Estado, na forma de suas autoridades, deve zelar sempre pelo interesse público.

Tendo em vista que o poluidor deve, em princípio, arcar com o custo decorrente da poluição, as autoridades nacionais devem promover a internalização dos custos ambientais e o uso de instrumentos econômicos, levando na devida conta o interesse público, sem distorcer o comércio e os investimentos internacionais (ONU, 1992).

Ainda na mesma oportunidade foi discutido o princípio da precaução, pois possui uma importância ímpar, visto que é praticamente impossível reparar o dano de forma a legar ao ambiente a seu status quo. E também que nenhuma quantia, por maior que seja, terá o condão de trazer qualquer benefício frente à destruição já causada (ONU, 1992).

O vocábulo "precaução" pode ser entendido como prudência, o ato de agir com moderação e sensatez. Foi um conceito trazido também pelas Nações Unidas na Conferência sobre Meio Ambiente e Desenvolvimento, e muito embora seja um princípio adotado pelo 
Estado brasileiro não encontra efetividade. Isso porque, o Poder Legislativo foi ineficiente na incumbência de criar diretrizes de aplicação concreta (ANTUNES, 2020).

Desse modo, importantes preceitos acabam por sucumbir ao julgo da inércia do Poder Público, em um país no qual existem muitas leis e maravilhosos princípios que sucumbem aos interesses individuais, acabando por deixar desassistida a coletividade.

Nesse sentido, o direito contemporâneo, por se deparar a cada instante com novos danos, passa a ampliar o próprio conceito jurídico de dano, o que se deve ao ativismo judicial recorrente, considerando a lacuna deixada pelo Executivo e pelo Legislativo (BAGATINI; ADOLFO, 2016, p.8)

É de relevância inegável o papel do judiciário em meio a proteção ambiental, pois leva a aplicação concreta os diplomas legais, todavia sendo praticamente impossível chegar a um padrão devido à variedade de casos com esta temática. Ainda que a legislação ambiental cresça potencialmente, também ela não seria efetiva frente a enormidade de possibilidades de lesões ao ambiente. A solução para o impasse, portanto, se encontra no comportamento ativo do órgão executivo, de forma a criar políticas públicas e ações de grande impacto quanto ao tema (ANTUNES, 2020).

Ao longo dos anos foi percebido, sobretudo em âmbito corporativo, que a poluição e a degradação ambiental geram efeitos a toda sociedade, enquanto o lucro obtido com atividades exploratórias, é individual. Assim, pode-se afirmar que a responsabilização civil ambiental, além de servir para defesa do meio ambiente, é meio de justiça social (SOUZA, 2014).

\section{DA RESPONSABILIDADE CIVIL OBJETIVA - A ADOÇÃO DA TEORIA DO RISCO INTEGRAL PARA OS DANOS AMBIENTAIS}

Ao reconhecimento da Constituição Federal de 1988, em seu capítulo VIII Da Ordem Social, Capítulo VI, Do Meio Ambiente, estabelece maneiras de reparação do dano ambiental, havendo três tipos de responsabilidade: civil, penal e administrativa, sendo elas independentes e autônomas entre si.

Art. 225. Todos têm direito ao meio ambiente ecologicamente equilibrado, bem de uso comum do povo e essencial à sadia qualidade de vida, impondo-se ao poder público e à coletividade o dever de defendê-lo e preservá-lo para as presentes e futuras gerações (BRASIL, 1988). 
De acordo com o artigo citado, em seu terceiro parágrafo, (Art. $225 \S 3^{\circ}$ da $\mathrm{CF} / 88$ ), a responsabilidade pelos danos ambientais é objetiva: "As condutas e atividades consideradas lesivas ao meio ambiente sujeitarão os infratores, pessoas físicas ou jurídicas, a sanções penais e administrativas, independentemente da obrigação de reparar os danos causados" (BRASIL, 1988).

A responsabilidade civil objetiva é caracterizada por não existir culpa, tratando, assim, o dano e não a conduta do agente.

\begin{abstract}
A responsabilidade civil objetiva é a responsabilidade sem culpa, o cerne dessa é o dano e não a conduta ou o comportamento do agente. Desta forma, a teoria objetiva, na imputação da responsabilidade ao causador de uma atividade lesiva ao meio ambiente, se afirma em razão do caráter de irreversibilidade dos danos ambientais (via de regra), da multiplicação dos fatores que originam o dano e também pela dificuldade de prova do elemento subjetivo - a culpa (COLOMBO, 2016).
\end{abstract}

Com o enfoque sendo a responsabilidade civil ambiental do tema tratado, que a partir da mesma, impõe a obrigação de que haja a reparação do dano causado a outrem, seja este dano ocasionado por uma ação ou omissão que gerou um prejuízo a ser solucionado (COLOMBO, 2016).

Observa-se que a doutrina pátria adere a teoria do risco integral no Direito Ambiental, não admitindo assim nenhum tipo de excludentes em danos ao meio ambiente, como explana Colombo (apud MANCUSO, 2016) sobre o tema, em resultado disto, o dever de indenizar, independe da verificação da culpa do agente, "Se constituindo numa solução apropriada para a garantia dos direitos das vítimas em se tratando de danos ambientais".

A exemplo de reparação de danos e como fundamento da indenização, o Novo Código Civil prevê, artigo 927, a obrigação de reparar o dano causado a outrem, disposto em seu parágrafo único.

Como também, a lei 6.938/81, que trouxe inovações na responsabilidade ambiental, introduzindo novos paradigmas e conceitos, preceituando o art. art. 14, § $1^{\circ}$ da Lei 6938/81:

Art $14-[\ldots] \S 1^{\circ}-$ Sem obstar a aplicação das penalidades previstas neste artigo, é o poluidor obrigado, independentemente da existência de culpa, a indenizar ou reparar os danos causados ao meio ambiente e a terceiros, afetados por sua atividade. $\mathrm{O}$ Ministério Público da União e dos Estados terá legitimidade para propor ação de responsabilidade civil e criminal, por danos causados ao meio ambiente." (BRASIL, 1981). 
Ou seja, há a independência da existência de culpa, se, na teoria subjetiva da responsabilidade, a culpa, dano, e o nexo de causalidade devem ser provados, na teoria objetiva, não se faz necessário avaliação a culpa do agente poluidor, pois é suficiente a existência do dano e a prova do nexo de causalidade da fonte poluidora (COLOMBO, 2019).

Por sua base obrigacional de reparação do dano, na sua forma objetiva, baseada na teoria do risco integral, funda-se a ideia que o causador (diretamente ou indiretamente) do dano se obriga a repará-lo, bastando apenas a prova da ação ou omissão, do dano e do nexo de causalidade como citado anteriormente.

Abordando, na íntegra, acerca da responsabilidade civil objetiva ambiental, há também a teoria do risco-proveito, além do risco integral. A teoria do risco-proveito está atrelada ao dever de indenizar a um proveito obtido pelo agente, sendo aquele que adquire lucro através de uma determinada atividade, e possui o dever de arcar com os prejuízos causados ao meio ambiente, admitindo, causas de exclusão, ou diminuição de responsabilidade, como o caso fortuito e a força maior, a intervenção de terceiros e, em alguns casos, a licitude da atividade poluidora.

A teoria do risco integral não admite as excludentes da culpa da vítima, o dever de indenização permanece mesmo havendo dano proveniente, a exemplo de força maior, e, a ilicitude ou não da conduta do agente é irrelevante para a caracterização da responsabilidade.

Portanto, por ser teoria majoritária, a maioria da doutrina Ambiental, adere à teoria do risco integral, caracterizando assim, a desconsideração da ilicitude do ato poluidor e a irrelevância do dano e sua intenção para ressarcir o dano causado ao meio ambiente.

\section{RESPONSABILIDADE CIVIL SOLIDÁRIA E INTEGRAL NO ÂMBITO CÍVEL}

As reparações civis passam a ser efetuadas para compensar os danos ambientais causados, com o objetivo de repor o "status quo ante", que é o estado original ou, caso seja impossível, converter o dano em indenização pecuniária (BRANDÃO, 2019).

O marco histórico da Revolução Industrial, com a massificação dos meios de produção e o consequente desenvolvimento de grandes corporações, legou ao mundo uma intensa urbanização. Fato este que elevou exponencialmente o potencial lesivo da sociedade ao meio ambiente, e que ainda aumenta ano após ano. É com o fim de coibir, ou mesmo de tentar amenizar tais lesões que nasce a responsabilização (BAGATINI; ADOLFO, 2016).

No direito civil, a responsabilidade contratual é regida pelo princípio adicional de "Aquiliana" ou responsabilidade subjetiva, que considera a culpa ou intenção do agente que 
causou o dano. Portanto, as atividades econômicas refletem o uso excessivo de recursos naturais, sendo calorosamente recebido pela sociedade para fortalecer as regras de responsabilidade na área ambiental (BRANDÃO, 2019).

\footnotetext{
Art. 927. Aquele que, por ato ilícito (arts. 186 e 187), causar dano a outrem, fica obrigado a repará-lo.

Parágrafo único. Haverá obrigação de reparar o dano, independentemente de culpa, nos casos especificados em lei, ou quando a atividade normalmente desenvolvida pelo autor do dano implicar, por sua natureza, risco para os direitos de outrem (BRASIL, 2002).
}

Quanto aos danos, há perdas materiais e perdas imateriais. A dimensão física envolve a hipótese real de identificação da lesão e envolve seus requisitos de reparo. Dimensões fora do balanço patrimonial impactam negativamente o dano social e moral coletivo (BRAUNER; SILVA, 2016).

Isso significa que quando o dano não pode ser identificado individualmente, parte do dano é atribuída a cada causa, assim, o dano como um todo será analisado. Por exemplo, uma indústria ou grupo industrial completo, às vezes é impossível encontrar todas as fontes de poluição que causam danos ambientais. Razões pelas quais a vítima não precisa procurar proteção judicial para cada um dos poluidores, pois você pode escolher o poluente que mais lhe convier para atender aos requisitos (BRANDÃO, 2019).

Diante de tudo, observa-se que a legislação civil deve ser rigorosa quanto à responsabilidade indenizatória por dano ambiental, estipulando responsabilidade objetiva, solidária e integral.

\section{CONSIDERAÇÕES FINAIS}

Diante de todo o exposto, foi possível entender que a própria Constituição Federal brasileira, aderindo ao caráter social, traz o direito a um meio ambiente ecologicamente equilibrado como fundamental a uma vida sadia. Prevê ainda o diploma legal, que pertence a coletividade e ao poder público o zelo pelo ambiente, como legado as gerações vindouras.

Por este motivo deve ser adotado sempre que possível o princípio da precaução, no qual os indivíduos mantêm suas condutas apoiadas no comedimento e em uma atuação pacífica. Pois uma vez lesado o ambiente é quase impossível que haja o regresso ao estado em que se encontrava. 
Assim sendo, para proteger este bem jurídico essencial, aos agentes causadores de dano ambiental parece justa a responsabilização objetiva, a qual independe a demonstração de dolo ou culpa, bastando para a configuração do crime apenas a ação ou omissão do indivíduo. A doutrina majoritária também defende a teoria do risco integral no que concerne a esta temática, não admitindo também qualquer tipo de excludente de ilicitude em tais casos.

A reparação de danos é elemento basilar ao direito civil brasileiro, presente no artigo 927 do código de leis civis, o qual assevera a obrigação de reparar o dano causado a outrem. Isto posto, para caracterização da responsabilidade objetiva basta apenas que se configure o dano e do nexo de causalidade da fonte poluidora.

Neste ínterim, é possível observar que as maiores agressões ocorrem em cenário corporativo. E nos casos em que não seja possível identificar o real causador, pelo número de empresas instaladas no local, a vítima pode procurar proteção judicial a apenas uma das empresas, respondendo as demais de forma solidária.

Fica claro, portanto que ao ordenamento jurídico brasileiro, bem como a toda coletividade, cabe o dever de guarda pelo ambiente, pois trata-se de bem atemporal e de inestimável valor. Razão pela qual a responsabilização por lesões deve ser objetiva, solidária a integral.

\section{REFERÊNCIAS BIBLIOGRÁFICAS}

ANTUNES. Paulo de Bessa. Os princípios da precaução e da prevenção no direito ambiental. Enciclopédia Jurídica da PUC-SP - Direitos Difusos e Coletivos. São Paulo, 2020. Disponível em: <https://enciclopediajuridica.pucsp.br/verbete/330/edicao-1/os-principios-daprecaucao-e-da-prevencao-no-direito-ambiental>. Acesso em: 26 mai. 2021.

BAGATINI, Júlia; ADOLFO, Luiz Gonzaga Silva. A responsabilidade civil à luz da solidariedade na sociedade de risco: construindo um direito de danos. XIII Seminário Internacional - Demandas sociais e políticas públicas na sociedade contemporânea, 2016. Disponível em: <https://online.unisc.br/acadnet/anais/index.php/sidspp/article/view/15761>. Acesso em: 27 mai. 2021.

BRANDÃO, Pedro Rodrigo Cavalcante. Responsabilidade ambiental: análise dos fundamentos e instrumentos jurídicos para coibir lesões ao meio ambiente. Revista Acadêmica Escola Superior do Ministério Público do Ceará, 2019. Disponível em: $<$ https://www.google.com/url?sa=t\&rct=j\&q=\&esrc=s\&source=web\&cd=\&ved=2ahUKEwi4 $372 \mathrm{Gg}-$

rwAhVXGbkGHaFsAbcQFjABegQIAxAD\&url=http\%3A\%2F\%2Fwww.mpce.mp.br\%2Fwp -content\%2Fuploads\%2F2019\%2F12\%2FARTIGO10.pdf\&usg=AOvVaw1J8xsvtXGFyOeEPNDt674B> . Acesso em: 27 mai. 2021. 
BRAUNER, Maria Claudia Crespo; SILVA, Carina Goulart da. A tríplice responsabilidade ambiental e a responsabilidade penal da pessoa jurídica.

Universidade Federal do Rio Grande do Norte, Juris - Revista da Faculdade de Direito, v. 26, p. 71-87, 2016. Disponível em: <https://periodicos.furg.br/juris/article/view/5882>. Acesso em: 27 mai. 2021.

BRASIL. Constituição da República Federativa do Brasil de 1988. Disponível em: <http://www.planalto.gov.br/ccivil_03/constituicao/constituicao.htm>. Acesso em: 25 mai. 2021.

BRASIL. Lei no 6.938, de 31 de agosto de 1981. Disponível em:

<http://www.planalto.gov.br/ccivil_03/leis/16938.htm>. Acesso em: 26 mai. 2021.

BRASIL. Lei $\mathbf{n}^{\mathbf{0}}$ 10.406, de 10 de janeiro de 2002. Disponível em:

<http://www.planalto.gov.br/ccivil_03/leis/2002/110406compilada.htm>. Acesso em: 27 mai. 2021.

COLOMBO, Silvana., A responsabilidade civil objetiva no Direito Ambiental. Disponível em:

$<$ https://periodicos.feevale.br/seer/index.php/revistagestaoedesenvolvimento/article/view/892 $>$. Acesso em: 24 mai. 2021.

ONU. Declaração do Rio de Janeiro, 1992. Disponível em:

<http://www.scielo.br/j/ea/a/szzGBPjxPqnTsHsnMSxFWPL/?lang=pt>. Acesso em: 25 mai. 2021.

SOUZA, Manahem David Dansiger de. Princípio do poluidor-pagador no Direito Ambiental. Revista Conteúdo Jurídico. Disponível em:

$<$ https://conteudojuridico.com.br/consulta/Artigos/42158/principio-do-poluidor-pagador-nodireito-ambiental>. Acesso em: 25 mai. 2021. 